\title{
Centrosome changes during meiosis in horse oocytes and first embryonic cell cycle organization following parthenogenesis, fertilization and nuclear transfer
}

\author{
Xihe Li, Y Qin", Sandra Wilsher and W R Allen \\ University of Cambridge, Department of Veterinary Medicine Equine Fertility Unit, Mertoun Paddocks, \\ Woodditton Road, Newmarket, Suffolk CB8 9BH, UK and ${ }^{7}$ China Agricultural University, College of Animal \\ Science and Technology, Equine Research Center, No. 2 Yuanmingyuan Xilu, Beijing 100049, China
}

Correspondence should be addressed to W R Allen; Email: efu@tesco.net

$\mathrm{X} \mathrm{Li}$ is now at China Agricultural University, College of Animal Science and Technology, Equine Research Center, No. 2 Yuanmingyuan Xilu, Beijing 100049, China

\begin{abstract}
Various types of cell cycle organization occur in mammals. In this study, centrosome changes during meiosis in horse oocytes, and first cell cycle organization following fertilization, parthenogenesis and nuclear transfer, were monitored. Cumulus oocyte complexes harvested from horse ovaries obtained from slaughtered mares were cultured in vitro. Meiotic oocytes of germinal vesicle (GV), germinal vesicle breakdown (GVBD), metaphase I and II (MI and MII) stages were selected at various set times during in vitro maturation. Embryos at the first cell cycle stage were generated by subjecting MII stage oocytes to fertilization by intracytoplasmic sperm injection (ICSI), parthenogenetic treatment or nuclear transfer. Centrosome changes during meiosis and the first cell cycle organization were detected by indirect immunofluorescent staining, using a mouse anti- $\alpha$-tubulin antibody for microtubules and a rabbit anti- $\gamma$-tubulin antibody for centrosomes. These examinations showed that the centrosomes of the horse oocyte reorganize themselves from the beginning of GV stage to leave only PCM of $\gamma$-tubulin surrounding both poles of the MI and MII stage spindles. These MII oocytes can organize the separation of metaphase chromosomes during the first embryonic cell cycle by parthenogenetic treatment. When the MII oocytes were subjected to ICSI or nuclear transfer, one or two red-stained centrosomes of $\gamma$-tubulin were introduced by the fertilising spermatozoon or the donor cell which associated with the sperm chromatin in the fertilized embryos and with the donor cell chromatin and microtubules in the cloned embryos. This finding suggests that centrosomes are not an essential component in the formation of the metaphase spindle during meiotic maturation of horse oocytes, but they can be introduced from the spermatozoon or donor cell and are necessary for the organization of normal embryonic development.

Reproduction (2006) 131 661-667
\end{abstract}

\section{Introduction}

The centrosomes are found at the poles of mitotic spindles, which are microtubule-organizing centres (MTOC) of mammalian cells during the cycle of somatic division (Kirschner \& Mitchison 1986, Mazia 1987, Nurse 1990, Karp 1999). Centrosomes are typically composed of two elements, centrioles and pericentriolar material (PCM). Although centrioles are part of centrosomes, they may not be essential for the meiotic spindles when oocytes are generated from germ line cells and their microtubules are still organized by PCM, which occurs during mammalian oogenesis (Laemmli 1972, Szollosi et al. 1972, Maro et al. 1985, Taieb et al. 1997, Karp 1999).

The patterns of centrosome inheritance during gametogenesis and fertilization differ among the different mammalian species and very little information relevant to this subject is available for the horse. Mouse oocytes are strongly supported by the presence of a population of non-spindle associated microtubule organizing centres which are not present in other mammalian species of pig, bovine and horse, in which the reconstitution of the centrosome inheritance may therefore differ (Schatten 1994, Simerly et al. 1999, Dai et al. 2000, Tremoleda et al. 2001, Shin et al. 2002). Furthermore, attempts to produce horse embryos by in vitro techniques have produced much lower success rates than in other domestic animal species and we still do not understand the reason why, especially in relation to first cell cycle organization following fertilization by ICSI or reconstruction by nuclear transfer (Hinrichs et al. 1993, Navara et al. 1996, Li et al. 
2001, 2002, 2003, Choi 2002, 2003, Woods et al. 2003, Galli et al. 2003). Therefore, in the present experiment, we studied the behaviour of centrosomes during the meiotic cell cycle, and their function at the first embryonic cell cycle, in embryos produced in vitro by parthenogenesis, ICSI-fertilization and nuclear transfer.

\section{Materials and Methods}

\section{Preparation of oocytes}

Horse ovaries were obtained from a commercial abattoir and cumulus oocyte complexes (COCs) were recovered by scraping the walls of follicles $0.5-3.0 \mathrm{~cm}$ in diameter. Meiotic oocytes of germinal vesicle (GV), germinal vesicle breakdown (GVBD), metaphase I and II (MI and MII) stages were prepared from groups of 20-30 COCs cultured in vitro for 4, 12, 20 and $28-30 \mathrm{~h}$, respectively. Culture conditions were at $38{ }^{\circ} \mathrm{C}$ in $5 \% \mathrm{CO}_{2}$-in-air in TCM199 (Sigma Chemicals, St Louis, USA) supplemented with $10 \% \mathrm{v} / \mathrm{v}$ heat inactivated fetal bovine serum, $10 \mu \mathrm{g} / \mathrm{ml} \mathrm{FSH}, 5 \mu \mathrm{g} / \mathrm{ml} \mathrm{LH}, 1 \mu \mathrm{g} / \mathrm{ml}$ oestradiol and $200 \mathrm{ng} / \mathrm{ml}$ IGF-I (all from Sigma). The same medium was used to culture the oocytes after parthenogenetic treatment, fertilization by ICSI and reconstruction by nuclear transfer.

\section{Parthenogenesis, ICSI-fertilization and nuclear transfer treatments}

MII oocytes were subjected to parthenogenetic stimulation, ICSI-fertilization or nuclear transfer using somatic cells, as described previously by Li et al. (2002, 2003 2004). For ICSI-fertilization, MII oocytes that had been matured for 28-30h in vitro had their cumulus cells removed before a whole sperm was injected into their cytoplasm. MII stage oocytes were also used for nuclear transfer and their nuclei were removed before a somatic cell was injected into the cytoplasm. After both sperm injection and nuclear transfer, the oocytes were activated chemically by immersing them in PBS containing $5 \mu \mathrm{M}$ ionomycin for $5 \mathrm{~min}$, followed by culture for $4 \mathrm{~h}$ in TCM199 medium containing $5 \mu \mathrm{g} / \mathrm{ml}$ cytochalasin B (Sigma) and $10 \mu \mathrm{g} / \mathrm{ml}$ cycloheximide (Sigma). To induce parthenogenesis, MII stage oocytes were subjected to the same culture conditions applied to activate the reconstructed oocytes. Groups of 5-10 treated nuclear transfer oocytes in the 3 experiments were then cultured in $500 \mu \mathrm{l}$ drops of development medium at $38^{\circ} \mathrm{C}$ in an atmosphere of $5 \% \mathrm{CO}_{2}$-in-air. The treated oocytes in each group were fixed $2-4,12-15$ and $20-24 \mathrm{~h}$, respectively, after activation to observe their first mitotic cell cycle.

\section{Centrosome, microtubule and chromatin analyses}

Oocytes were selected at various stage of meiosis, or after parthenogenetic stimulation, ICSI-fertilization or nuclear transfer. They were fixed initially by immersion for $1 \mathrm{~h}$ at $38^{\circ} \mathrm{C}$ in $\mathrm{M}$ medium (Simerly \& Schatten 1993) followed by $2.5 \%$ paraformaldehyde for $30 \mathrm{~min}$. Their microtubules and centrosomes were labeled by incubating the fixed oocytes for $90 \mathrm{~min}$ at $38{ }^{\circ} \mathrm{C}$ in a mixture of a mouse anti$\alpha$-tubulin antibody (Sigma) and a rabbit anti- $\gamma$-tubulin antibody (Sigma), all diluted 1:250 in PBS containing $3 \mathrm{mg}$ $\mathrm{ml}^{-1}$ BSA. They were then incubated for a further $1 \mathrm{~h}$ in a blocking solution of $10 \% \mathrm{v} / \mathrm{v}$ goat serum in PBS after which they were exposed for $1 \mathrm{~h}$ at $38^{\circ} \mathrm{C}$ to the respective second antibody, each diluted 1:250 in PBS containing $0.5 \%$ Triton X-100 and $0.5 \%$ BSA. FITC-conjugated goat anti-mouse globulin (Sigma) stained the microtubules green and Alexa Flour 568-conjugated goat anti-rabbit globulin (Sigma) stained the centrosomes red. The stained oocytes were then mounted under a coverslip in an antifade mounting medium containing TOTO3 (Sigma; stains chromatin blue) and examined by confocal microscopy.

All the animals used in these experiments were licensed (Project no. PPL 80/1442) and maintained (Certificate of Designation no. PCD 80/9044) under the provision of the Animals (Scientific Procedures) Act 1986, and under the supervision of the Home Office Experimental Animal Inspectorate.

\section{Results}

\section{Meiotic organization}

A total of 286 COCs were used in the study and 63, 56, 67 and 100 oocytes respectively were analysed for GV, GVBD, MI and MII stages, which included the treatments for parthenogenesis, ICSI and nuclear transfer (Table 1). Staining with TOTO3 for DNA, and both positive and negative controls when staining with the mouse anti- $\alpha$ tubulin antibody (Sigma) for microtubules, and a rabbit anti- $\boldsymbol{\gamma}$-tubulin antibody (Sigma) for centrosomes, are shown in Fig. 1. The meiotic organisation of the horse oocyte from GV to the MII stage is shown in Fig. 2. Microtubule organisation is not seen during the condensation of chromatin DNA that occurs at the beginning of meiosis at the GV stage (Figs 2A and B). It appeared, and it forms the spindle net, at the $\mathrm{MI}$ and the MII stages (Figs 2E-G). The centrioles are not seen during the whole meiotic process when there are only some PCM structures of $\gamma$-tubulin surrounding both poles of the $\mathrm{MI}$ and $\mathrm{MII}$ stage spindles. This is associated with chromosome separation to release the

Table 1 Horse oocyte maturation rates at different times of in vitro culture.

\begin{tabular}{lccccc}
\hline & & \multicolumn{4}{c}{ No. oocytes (\%) } \\
\cline { 3 - 6 } $\begin{array}{l}\text { Time in } \\
\text { culture }(h)\end{array}$ & No. COCs used & GV & GVBD & MI & MII \\
\hline 4 & 55 & $37(67)$ & $16(29)$ & $2(4)$ & 0 \\
12 & 46 & $8(18)$ & $17(37)$ & $21(45)$ & 0 \\
20 & 47 & $4(9)$ & $12(26)$ & $26(56)$ & $5(11)$ \\
$28-30$ & 138 & $14(10)$ & $11(8)$ & $18(13)$ & $95(69)$ \\
\hline
\end{tabular}



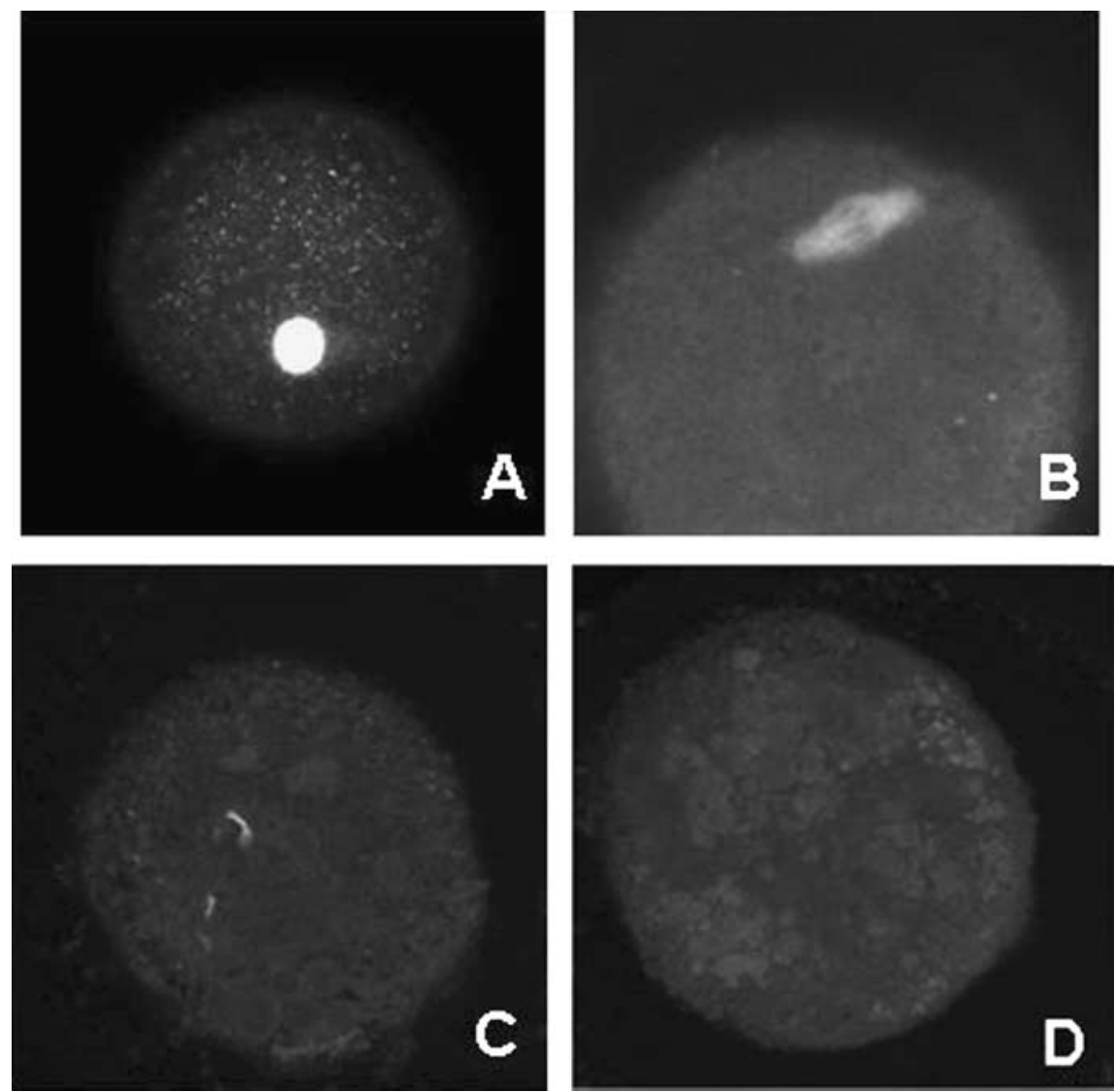

Figure 1 Staining test for DNA, microtubules and centrosomes. (A) DNA was stained by TOTO3; (B) microtubules and centrosomes were stained with mouse anti- $\alpha$-tubulin antibody; (C \& D) microtubules and centrosomes were stained with a rabbit anti- $\gamma$-tubulin antibody. C, positive; D, negative control, respectively.
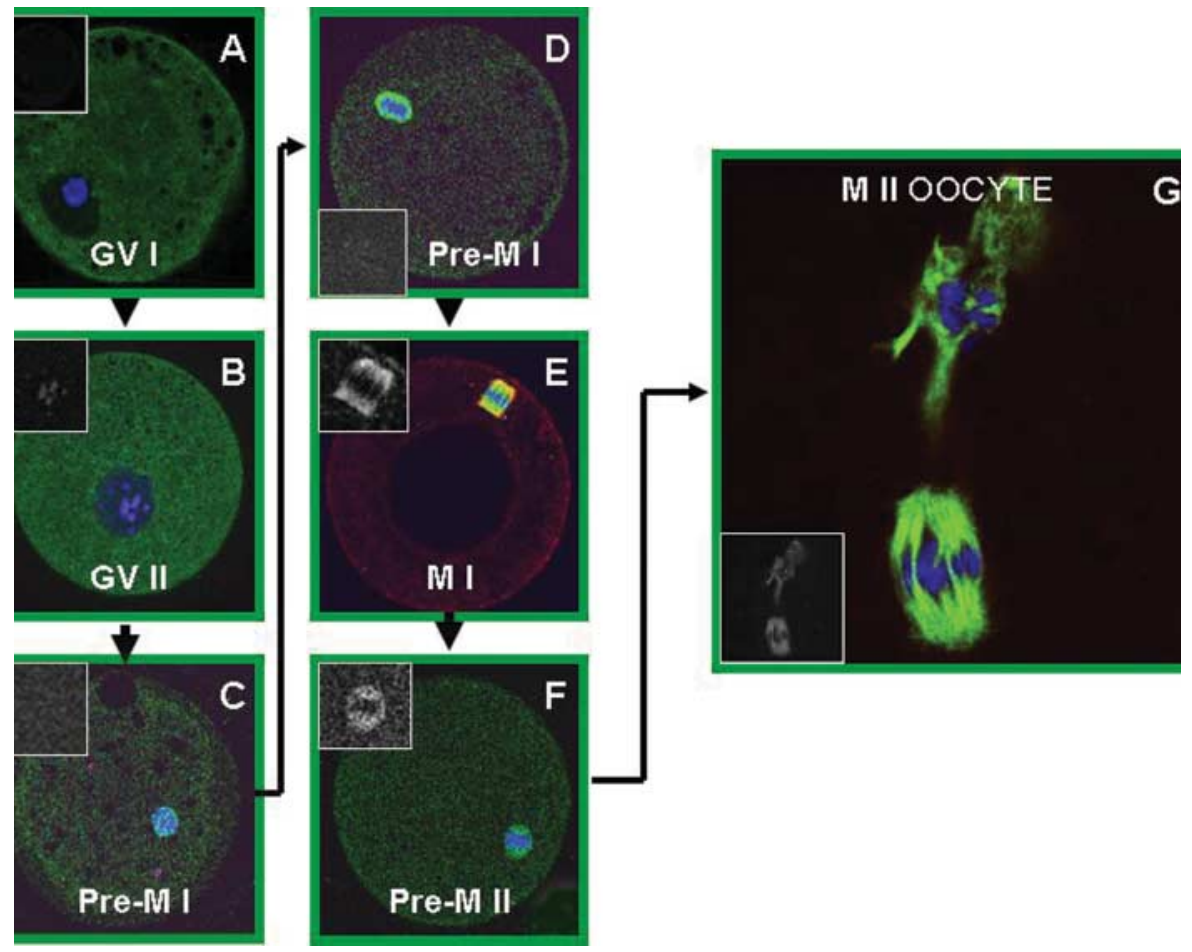

Figure 2 Meiotic cell cycle organisation in horse oocytes from G1 to MII stages. The inset shows $\gamma$-tubulin staining on each photograph. The oocytes were stained for microtubules; $\alpha$-tubulin, FITC-green; $\boldsymbol{\gamma}$-tubulin, Texas-red and chromatin, TOTO3-blue. The G1 stage oocyte shows condensed chromatin (A, GVI) and it has begun to form chromosomes (B, GVII). Microtubules are seen in pro-metaphase $(\mathrm{C})$ which circle the chromatin before passing into the first metaphase stage (D), without any activity in the centrosome throughout this period $(A-D)$. The red $\gamma$-tubulin material occurs at the spindle poles in the first metaphase stage (E), and it persists until the pro- $(\mathrm{F})$ and second metaphase $(\mathrm{G})$ stages. 
first polar body and, subsequently, the meiotic cycle stops at the MII stage (Fig. 2G).

\section{First cell cycle organisation in parthenogenetic and fertilized oocytes}

The chromosomes of MII oocytes separated following parthenogenetic treatment and the first cell cycle of embryonic development were organised under the actions of PCM (Figs $3 \mathrm{~A} 1-\mathrm{A} 3$ ), but not the centrioles. In the case of fertilization by ICSI, the centrosomes of the spermatozoon (Fig. 3B1) reorganised soon after the latter was injected into the MII oocyte (Fig. 3B2) and the first cell cycle of embryonic development was organised following formation of the male and female pronuclei (Figs 3B3 and
B4). In this case, the zygote or early embryo was constructed by the spermatozoon and oocyte each contributing half the genomic DNA while the centrosome came from the oocyte in the form of microtubules (Figs 3B3 and B4).

\section{First cell cycle organisation in cloned embryos}

The cell cycle organisation of cloned embryos is shown in Fig. 3. The centrosomes of the somatic cell (Fig. 3C1) injected into the cytoplasm of the enucleated MII oocyte were not observed following nuclear reprogramming (Fig. 3C2). However, more time was needed to generate microtubules than was required after fertilization, which was organised by one or two red-stained centrosome structures of $\gamma$-tubulin (Fig. 3C3). The generation of cen-
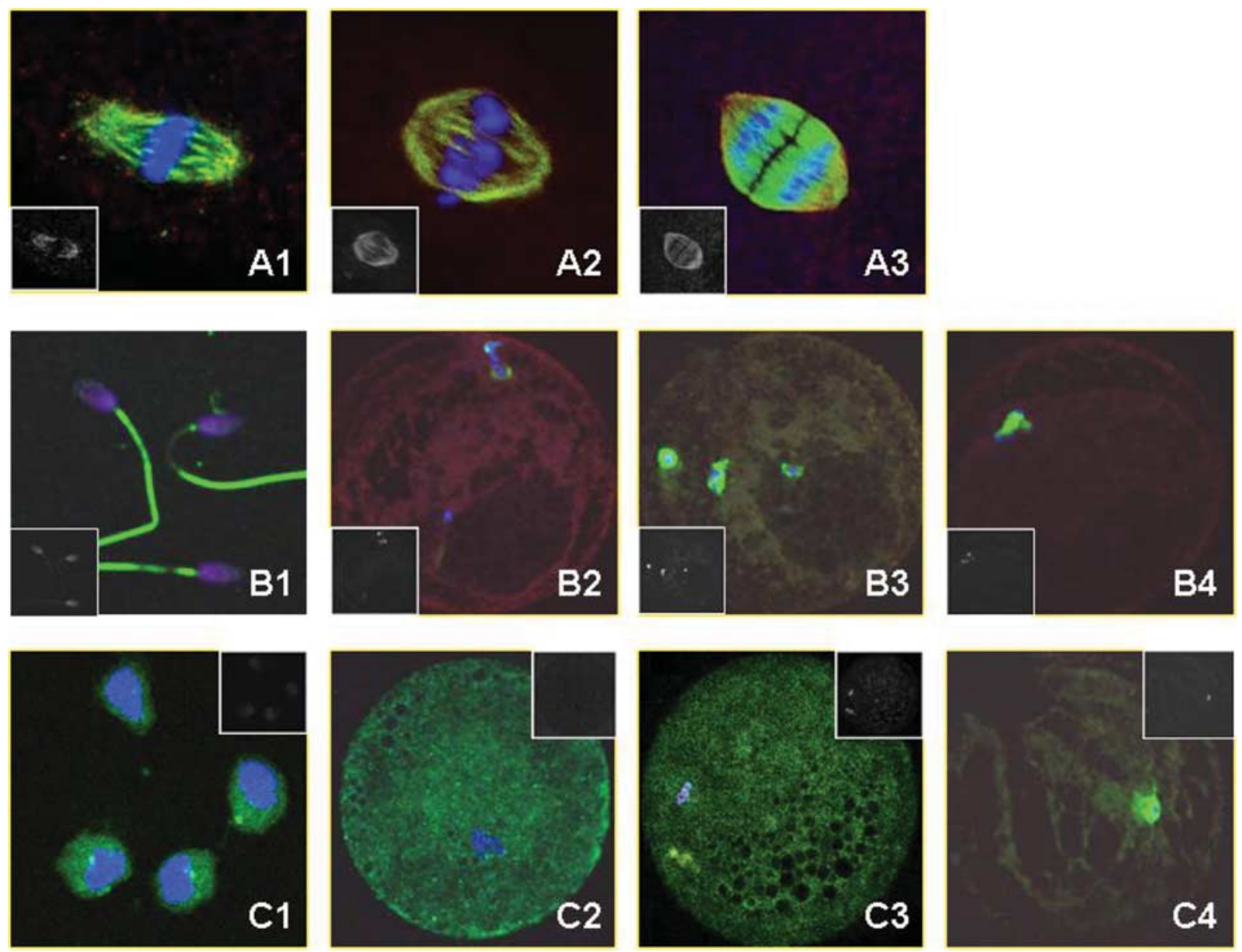

Figure 3 First cell cycle organisation of horse oocytes following parthenogenetic stimulation, ICSI-fertilization and nuclear transfer treatments. The oocytes were stained for microtubules; $\alpha$-tubulin, FITC-green; $\gamma$-tubulin, Texas-red and chromatin, TOTO3-blue. The inset shows $\gamma$-tubulin staining on each photograph. A1-A3, a MII oocyte (A1) that was activated parthenogenetically showing separation of the metaphase chromosomes after movement of the microtubules to the spindle poles (A2 and A3). Red stained $\gamma$-tubulin is more concentrated at the later stage of the first cell cycle, but it has not yet formed centrosomes (A3). B1-B4; a centrosome-like structure of red staining $\gamma$-tubulin is seen in the neck of the horse spermatozoon (B1). It reorganises soon after being injected into the cytoplasm (B2), followed by decondensation of the sperm chromatin DNA. A red stained deposit of $\gamma$-tubulin is seen again with the formation of the male pronucleus (B3). The centrosome reforms with a regular outline following male and female pronuclear fusion and this subsequently develops into the pre-metaphase stage at the first mitotic cell cycle of the fertilized oocyte (B4). C1-C4; a centrosome-like structure of red staining $\gamma$-tubulin is seen in the somatic cell nucleus (C1). When the cell fuses with the enucleated oocyte, the centrosome reorganises (C2) and this situation persists through to the formation of the pseudo-pronuclei (C3). Two red spots, indicating reforming centrosomes, are seen during the pre-metaphase stage at the first mitotic cell cycle (C4). 
trosomes provided by the somatic cell was associated with condensation of the chromatin DNA and metaphase chromosome formation at the first cell cycle of embryonic development (Fig. 3 C4).

A total of 30-50 oocytes were evaluated in each of the three treatments, parthenogenesis, ICSI and nuclear transfer. Details of first cell cycle organisation in the horse embryos created by ICSI, or reconstructed by nuclear transfer, are summarised in Figs $4 \mathrm{~A}$ and $\mathrm{B}$.

\section{Discussion}

Meiosis in the germ line halves the ploidy of the gametes, ensuring that the ploidy of the organism is maintained in the next generation. Similarly, the number of centrosomes must also be reduced during gametogenesis or fertilization to maintain the correct number of centrosomes in the zygote (LeGuen \& Crozet 1989, Taieb et al. 1997).

Centrioles are cylinders of microtubule triplets required for the generation of ciliary flagellar axonemes, and the PCM is an amorphous cloud that surrounds the centrioles and organizes the microtubules (Karp 1999). $\gamma$-tubulin, a new member of the tubulin superfamily that functions in microtubule nucleation, has been localized at the spindle poles and cytoplasmic MTOCs in mouse metaphase IIarrested oocytes (Oakley \& Oakley 1989, Joshi et al. 1992, Palacios et al. 1993). Therefore, despite the absence of a definitive centrosome, mouse meiotic spindles contain foci of PCM, including $\gamma$-tubulin, which probably nucleates meiotic spindle microtubules at the poles. On the other hand, cytoplasmic MTOC are not present in MII oocytes of pigs, sheep and cows, in contrast to mouse MII oocytes in which they have been found at the spindle poles and in the cytoplasm. Furthermore, several PCM foci can be seen at the acentriolar meiotic spindle poles of mouse oocytes, as well as in the cytoplasm (Maro et al. 1985, LeGuen \& Crozet 1989, Araki et al. 1996, Kim et al. 1996, Lee et al. 2000). Our results showed that, from the GV to the MII stage of meiosis in horse oocytes, there is only a PCM of $\gamma$-tubulin surrounding both poles of the MI and MII stage spindles (Figs 2A-G). These findings are similar to oogenesis in women and cows, but differ from that in mice (Simerly et al. 1999). In parthenogenetically activated oocytes, centrioles were also absent from both poles of the microtubular spindles following their further development after separation of the chromosomes (Figs $3 \mathrm{~A} 1-\mathrm{A} 3)$. However, red stained PCM of $\gamma$-tubulin did remain associated with the microtubules (Figs $3 \mathrm{~A} 1-\mathrm{A} 3$ ). These findings indicate that centrioles are not an essential component in the formation of the metaphase spindle during meiotic oogenesis in the horse.

In most species, the spermatozoon contributes the centrioles and the oocyte contributes the PCM to the zygotic centrosomes. However, there are some exceptions to this paternal inheritance of centrioles rule; for example, spermatogenesis in mice and parthenogenetic development in wasps (Messinger \& Albertini 1991, Schatten 1994). It has been generally understood that both duplication of the centrosome and variations in its microtubule-nucleating capacity are driven by cell cycle-dependent changes in the cytoplasmic environment (Nurse 1990, Pereira et al. 2000). In the present experiment, the presence of additional centrosomes was confirmed by $\gamma$-tubulin staining in both the horse spermatozoon and in somatic cells, concentrated respectively at the neck of the spermatozoon and the cytoplasm surrounding the nucleolus of the somatic cell (Figs 3B1 and C1; Figs 4A and B). When a spermatozoon was injected into the cytoplasm of an MII oocyte, the centrosome could not be detected after $4-6 \mathrm{~h}$ but it then reorganized itself again, becoming surrounded by microtubules following DNA decondensation in the sperm head (Figs 3B2 and B3). This result provided evidence that $\gamma$-tubulin of the sperm centrosome may induce the programming of the first cell cycle, from the MII stage oocyte into the zygote and subsequently into the embryo, by the organization of microtubules and chromatin (Figs 3B3 and B4; Fig. 4A).

Nuclear transfer is a relatively new reproductive technique in mammals. It has shown that breakdown of the nuclear envelope, premature chromosome condensation and swelling of the nucleus resulting in nuclear reprogramming, are all prerequisites for first cell cycle organization and further development of embryos created by nuclear transfer (Galli et al. 2003, Woods et al. 2003, Li et al. 2004). In nuclear transfer, the general idea is to replace the metaphase chromatin of the MII oocyte by the nucleolus of a somatic cell recovered from the donor animal. Briefly, the microtubules in the MII oocyte have been removed by the process of enucleation so the first cell cycle organization will progress differently compared with that following fertilization or parthenogenesis.

Previous studies have indicated that, after removal of the centrosome, both somatic and embryonic cells can regenerate a MTOC, but they do not regenerate centrioles even though the cytoplasm (in the case of zygotes) contains enough subunits to assemble many complete centrosomes (Bloecher \& Tatchell 2000). Our results related to the organization of first cell cycle in the reconstructed oocytes (Figs $3 \mathrm{C} 1-\mathrm{C} 4$ ) showed that the centrioles of the somatic cell (Fig. 3C1) degenerated in the cytoplasm of the enucleated oocyte, within a similar period of $4 \mathrm{~h}$ to that of DNA decondensation of the sperm head following ICSI-fertilization (Figs 3B2 and C2). However, more time was needed to generate microtubules $(12 \mathrm{~h})$, which were organized by 1 or 2 red-stained centrosome structures of $\gamma$-tubulin (Fig. 3C3, Fig. 4B). Furthermore, this appeared to be associated with the introduced donor chromatin following nuclear transfer (Figs 3C3 and C4; Fig. 4B). Thus, the suggestion arises that the centrioles which participate in the reorganization of the chromatin during the first cell cycle in cloned horse embryos may be contributed by the somatic donor cell (Fig. 4B). However, our study was not able to disprove the possible participation of the oocyte 


\section{A: Fertilization}

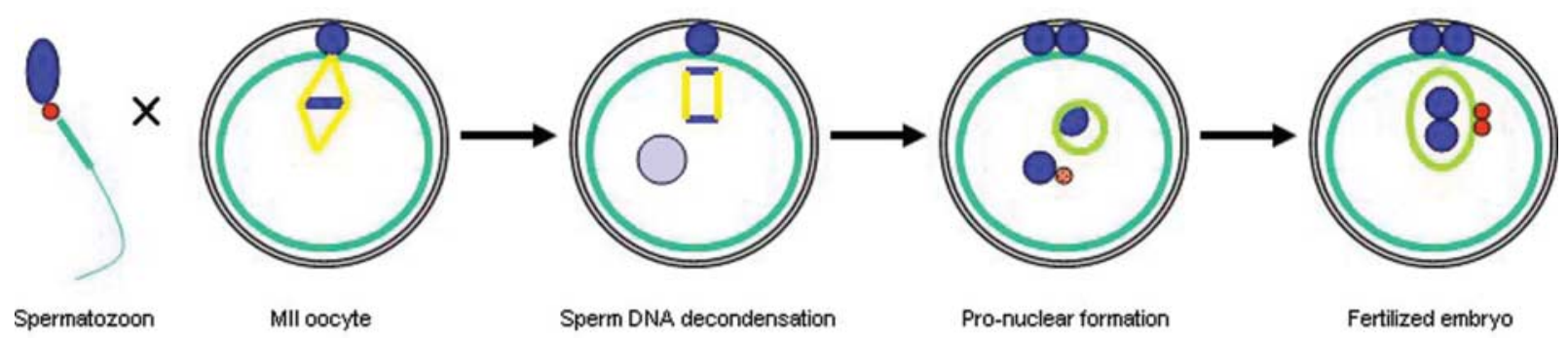

\section{B: Nuclear transfer}

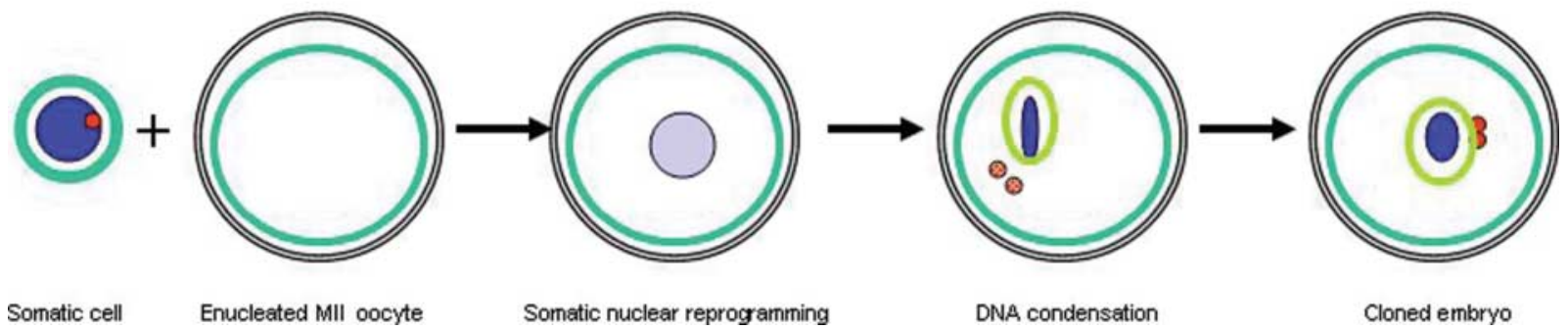

Figure 4 Visualisation of microtubules and centrosome- $\gamma$-tubulins during the first cell cycle organisation of the horse oocyte following ISCI-fertilization and reconstruction by nuclear transfer. (A) ICSI-fertilization; the centrosome reorganises as soon at the spermatozoon is injected into the MII oocyte, but then re-appears following organization of the microtubulues into the first cell cycle of mitosis. (B) Nuclear transfer; the centrosome reorganises following fusion of the donor cell with the enucleated cytoplasm, and then re-appears following nuclear reprogramming into the first cell cycle of mitosis.

cytoplasmic tubulin, which can be recruited during reconstitution of the zygotic centrosome, as seen in human and bovine early zygotes (Schatten 1994, Simerly et al. 1999). We propose that this block to microtubule reorganization may be an underlying reason for the lower success rates achieved for in vitro production of horse embryos, both following fertilization by ICSI and reconstruction by nuclear transfer (Li et al. 2003, 2004, Choi et al. 2003, Woods et al. 2003, Galli et al. 2003).

Taken together, the findings indicate that the techniques used presently to produce horse embryos in vitro need further investigations at the molecular level, combined with additional studies of significant morphological changes.

\section{Acknowledgements}

These studies were kindly financed by The Thoroughbred Breeders' Association and the Moller Charitable Trust. The authors are grateful to the staff of Potters' Horse Abattoir in Somerset, UK for the supply of horse ovaries. Dr Bao Siqin of the Wellcome CRC Institute, Cambridge University, kindly analysed the confocal laser scanning images of the oocytes. The authors declare that there is no conflict of interest that would prejudice the impartiality of this scientific work.

\section{References}

Araki K, Naito K, Haraguchi S, Suzuki R, Yokoyama M, Inoue M, Aizawa S, Toyoda Y \& Sato E 1996 Meiotic abnormalities of c-mos knockout mouse oocytes: activation after first meiosis or entrance into third meiotic metaphase. Biology of Reproduction 55 1315-1324.

Bloecher A \& Tatchell K 2000 Dynamic localization of protein phosphatase type 1 in the mitotic cell cycle of Saccharomyces cerevisiae. Journal of Cell Biology 149 125-140.

Choi YH, Love CB, Westhusin ME \& Hinrichs K 2003 Activation of equine nuclear transfer oocytes: Methods and timing of treatment in relation to nuclear remodeling. Biology of Reproduction $\mathbf{7 0}$ $46-53$.

Choi YH, Love CC, Chung YG, Varner DD, Westhusin ME, Burghardt RC \& Hinrichs K 2002 Production of nuclear transfer horse embryos by Piezo-driven injection of somatic cell nuclei and activation with stallion sperm cytosolic extract. Biology of Reproduction 67 561-567.

Dai Y, Lee C, Hutchings A, Sun Y \& Moor R 2000 Selective requirement for Cdc25C protein synthesis during meiotic progression in porcine oocytes. Biology of Reproduction 62 519-532.

Galli C, Lagutina I, Crotti G, Colleoni S, Turini P, Ponderato N, Duchi R \& Lazzari G 2003 A birth announcement calls for a rethink on the immunological demands of pregnancy. Nature $\mathbf{4 2 4} 635$.

Hinrichs K, Schmidt AL, Friedman PP, Selgrath JP \& Martin MG 1993 In vitro maturation of horse oocytes: characterization of chromatin configuration using fluorescence microscopy. Biology of Reproduction 48 363-370.

Joshi HC, Palacios MJ, McNamara L \& Cleveland DW 1992 Gammatubulin is a centrosomal protein required for cell cycle-dependent microtubule nucleation. Nature 356 80-83.

Karp G 1999 The cytoskeleton and cell motility. In Cell and Molecular Biology, edn 2, pp 344-412. New York: John Wiley \& Sons.

Kim NH, Funahashi H, Prather RS, Schatten G \& Day BN 1996 Microtubule and microfilament dynamics in porcine oocytes during meiotic maturation. Molecular Reproduction and Development 43 248-255. 
Kirschener M \& Mitchison TJ 1986 Beyond self-assembly: from microtubules to morphogenesis. Cell 45 329-342.

Laemmli UK 1970 Cleavage of structural proteins during the assembly of the head of bacteriophage T4. Nature 227 680-685.

LeGuen P \& Crozet N 1989 Microtubule and centrosome distribution during sheep fertilization. European Journal of Cell Biology 48 239-249.

Lee J, Miyano T \& Moor RM 2000 Spindle formation and dynamics of gamma-tubulin and nuclear mitotic apparatus protein distribution during meiosis in pig and mouse oocytes. Biology of Reproduction 62 1184-1192.

Li X, Morris LHA \& Allen WR 2000 Effects of different activation treatments on fertilization of horse oocytes by ICSI. Journal of Reproduction and Fertility 119 253-260.

Li X, Morris LHA \& Allen WR 2001 The influence of co-culture during maturation on the developmental potential of equine oocytes fertilized by intracytoplasmic sperm injection (ICSI). Reproduction 121 925-932.

Li X, Morris LHA \& Allen WR 2002 In vitro development of horse oocytes reconstructed with the nuclei of fetal and adult cells. Biology of Reproduction 66 1288-1292.

Li X, Tremoleda JL \& Allen WR 2003 Effect of the number of passages of fetal and adult fibroblasts on nuclear remodelling and first embryonic division in reconstructed horse oocytes after nuclear transfer. Reproduction 125 535-542.

Li X, Dai Y \& Allen WR 2004 Influence of insulin-like growth factor-I on cytoplasmic maturation of horse oocytes in vitro and organisation of the first cell cycle following nuclear transfer and parthenogenesis. Biology of Reproduction 71 1391-1396.

Maro B, Howlett SK \& Webb M 1985 Non-spindle microtubule organizing centers in metaphase II-arrested mouse oocytes. Journal of Cell Biology 101 1665-1672.

Mazia D 1987 The chromosome cycle and the centrosome cycle in the mitotic cycle. International Review of Cytology 100 49-92.

Messinger SM \& Albertini DF 1991 Centrosome and microtubule dynamics during meiotic progression in the mouse oocyte. Journal of Cell Science 100 289-298.

Navara CS, First NL \& Schatten G 1996 Phenotypic variations among paternal centrosomes expressed within the zygote as disparate microtubule lengths and sperm aster organization: Correlations between centrosome activity and developmental success. PNAS 93 5384-5388.

Nurse P 1990 Universal control mechanism regulating onset of M-phase. Nature 344 503-508.
Oakley CE \& Oakley BR 1989 Identification of gamma-tubulin, a new member of the tubulin superfamily encoded by the mipA gene of Aspergillus nidulans. Nature 338 662-664.

Palacios HJ, Joshi HC, Simerly C \& Schatten G 1993 Gamma-tubulin reorganization during mouse fertilization and early development. Journal of cell Science 104 383-389.

Pereira G, Hofken T, Grindlay J, Manson C \& Schiebel G 2000 The Bub2p spindle checkpoint links nuclear migration with miotic exit. Molecular Cell 6 1-10.

Schatten G 1994 Centrosome inheritance: the reduction of the centrosome during gametogenesis and its restoration during fertilization Developmental. Biology 165 299-335.

Shin MR, Park SW, Shin H \& Kim NH 2002 Nuclear and microtubule reorganization in nuclear-transferred bovine embryos. Molecular Reproduction and Development 62 74-82.

Simerly C \& Schatten 1993 Techniques for localization of specific molecules in oocytes and embryos. In Methods in Enzymology, pp 516-552. Eds PM Wassarman \& ML DePamphilis. New York: Academic Press

Simerly C, Zoran SS, Payno C, Dominko T, Sutovsky C, Navara CS, Salisbury JL \& Schatten G 1999 Biparental inheritance of $\gamma$-tubulin during human fertilization: molecular reconstitution of functional zygotic centrosomes in inseminated human oocytes and in cellfree extracts nucleated by human sperm. Molecular Biology of the Cell 10 2955-2969.

Szollosi D, Calarco P \& Donahue RP 1972 Absence of centriole in the first and second meiotic spindle of mouse oocytes. Journal of Cell Science 11 521-541.

Taieb F, Thibier C \& Jessus C 1997 On cyclins, oocytes and eggs. Molecular Reproduction and Development 48 397-411.

Tremoleda JL, Schoevers EJ, Stout TAE, Colenbrander B \& Bevers MM 2001 Organization of the cytoskeleton during in vitro maturation of horse oocytes. Molecular Reproduction and Development $60260-269$.

Woods GL, Vanderwall DK, Li GP, Aston KI, Bunch TD, Meerdo LN \& Pate BJ 2003 A mule cloned from fetal cells by nuclear transfer. Science 3011063.

Received 5 May 2005

First decision 4 July 2005

Revised manuscript received 15 December 2005

Accepted 19 January 2006 